\title{
Properties of Extruded Xanthan-Starch-Clay Nanocomposite Films
}

\author{
Cristina de Melo ${ }^{1}$, Patrícia Salomão Garcia ${ }^{2}$, Maria Victória Eiras Grossmann², Fábio \\ Yamashita $^{2}$, Luiz Henrique Dall'Antônia ${ }^{3}$ and Suzana Mali ${ }^{1^{*}}$ \\ ${ }^{1}$ Departamento de Bioquímica e Biotecnologia; Centro de Ciências Exatas; Universidade Estadual de Londrina; C. \\ P.: 6001; 86051-990; Londrina - PR - Brasil. ${ }^{2}$ Departamento de Ciência e Tecnologia de Alimentos; Centro de \\ Ciências Agrárias; Universidade Estadual de Londrina; C. P.: 6001; 86051-990; Londrina - PR - Brasil. \\ ${ }^{3}$ Departamento de Química; Centro de Ciências Exatas, C. P.: 6001; 86051-990; Londrina - PR - Brasil
}

\begin{abstract}
The aim of this work was to manufacture the biodegradable nanocomposite films by extrusion from different combinations of cassava starch, xanthan gum and nanoclays (sodium montmorillonite - MMT- Na) and to characterize them according to their microstructure, optical, mechanical and barrier properties. Films were manufactured from nine starch/xanthan/nanoclay combinations, containing glycerol as plasticizer. Scanning electron microscopy (SEM) of the starch-xanthan extruded films showed reticulated surface and smooth interior, indicating that the gum was mostly concentrated on the surface of the films, while starch/xanthan/nanoclays films showed a more homogeneous surface, suggesting that the introduction of nanoclays provided a better biopolymeric interaction. In general, nanoclays addition $(2.5-5.0, w \%)$ generated more transparent and resistant films, with lower water vapor permeabilities and lower water sorption capacities and xanthan gum addition improved the elongation of starch films.
\end{abstract}

Key words: film blowing; cassava starch; microstructure; mechanical properties; water vapor permeability

\section{INTRODUCTION}

Starch is considered one of the most promising natural polymers for packaging applications due to its low cost, abundance, and the possibility of producing the thermoplastic starch (TPS). TPS can be made from starch by various techniques, such as solution casting (Mali et al., 2005; 2006) or thermoplastic extrusion, which is a green and easy process when compared with casting (Wang et al., 2009). According to Thunwall et al. (2008), converting starch materials into films or coatings in a feasible manner requires energy-efficient techniques in combination with high productivity processes. Such processes should be preferably based on already existent converting technology like extrusion. Although TPS is being studied and used for many different food packaging applications, films based only on starch are sensitive to moisture and have poor mechanical properties. For this reason, the development of biodegradable packaging using starch demands the introduction of additives that could potentially enhance TPS functional properties (Wang et al., 2009).

*Author for correspondence: smali@uel.br 
Hydrocolloids such as xanthan gum represent a new frontier to be explored in the search for high efficiency biodegradable materials. It has been observed that the addition of hydrocolloids increases the viscosity of starch gels, affects starch gelatinization and retrogradation, improves the viscosity and viscoelasticity of starch solutions (Wang et al., 2001; Veiga-Santos et al., 2005; Achayuthakan, 2008), reduces starch aging and crystallization rate (Yoshimura et al., 1999), and helps to maintain the rheological properties of starch pastes after freezing (Navaro et al., 2005). Xanthan gum is an exopolysaccharide produced by the aerobic fermentation of Xanthomonas campestris and it has been traditionally used as stabilizer for the food, cosmetics and pharmaceutical formulations (García-Ochoa et al., 2000). According to Soares et al. (2005), the use of starch/xanthan blends to produce the biodegradable and/or edible films is promising and needs to be investigated.

Another method to improve TPS properties involves adding the nanoclays to starch formulations. The most commonly used nanoclays include montmorillonite (MMT), a kind of aluminum silicate classified as phyllosilicates, which is environmentally friendly, readily available, and relatively low cost. Nanoclays are characterized by a stacked platelet structure in which each platelet is approximately $1 \mathrm{~nm}$ thick with lateral dimensions on the order of micrometers. Unmodified nanoclays or natural sodium montmorillonite (MMT-Na) have a hydrophilic interlayer between each platelet enclosing an inorganic cation $\left(\mathrm{Na}^{+}\right)$(Chivrac et al., 2009). A wide range of nano-biocomposites have been elaborated combining nanoclays with different matrices (Chivrac et al., 2008), such as policaprolactone (Lepoittevin et al., 2002), polylactic acid (Paul et al., 2003), polyhydroxyalkanoates (Sanchez-Garcia et al., 2008) or with agro-polymers like starch or chitosan (Park et al., 2002; 2003), demonstrating that nano-biocomposites elaboration could be a powerful strategy to overcome the conventional drawbacks of agro-based polymers.

Nano-biocomposites based on glycerol plasticized starch (>10 wt\% of glycerol) and elaborated with MMT-Na form an intercalated structure, which result from the penetration of polymers chains into the interlayer region of the clay, resulting in an ordered multilayer structure with alternating polymer/inorganic layers at a repeated distance of a few nanometers (Weiss et al., 2006). MT addition can increase the mechanicall properties and thermal stability of starch films (Wang et al., 2009; Park et al., 2002; Dean et al., 2007), and according to Park et al. (2003), incorporating MMT at only 5\%wt has promoted the reduction of water vapor transmission rates by nearly one-half. The objectives of this work were to manufacture the biodegradable films from different combinations of cassava starch, xanthan gum and unmodified nanoclays (MMT-Na) by extrusion, as well to analyze the effects of each film formulation on the microstructure, water vapor permeability, optical and mechanical properties of these films.

\section{MATERIAL AND METHODS}

\section{Material}

Xanthan gum and analytically pure glycerol were obtained from Synth (São Paulo - SP, Brazil); cassava starch was obtained from Indemil Ltda (Paranavaí - PR, Brazil) and montmorillonite-Na was provided by Bentonisa (Bentonisa do Nordeste - Brazil). Analytically pure barium chloride, calcium chloride, lithium chloride, magnesium chloride, potassium chloride, sodium chloride, and sodium bromide, to prepare the saturated solutions for relative humidity film conditioning were obtained from Cinética Química Ltda (São Paulo - SP, Brazil).

\section{Films preparation}

The film formulations are shown in Table 1 . Control films formulated only with starch and glycerol (TPS) and films produced with starch, glycerol and xanthan (TPSX) were produced as follows: starch and glycerol (and xanthan in the films containing the gum) were manually mixed in the sealed plastic bags for $30 \mathrm{~min}$ and stored $24 \mathrm{~h}$ before extrusion.

Films formulated with starch, glycerol and MMT (TPS/ MMT) and with starch, glycerol, xanthan and MMT (TPSX/MMT) were prepared in two steps: initially, MMT was manually mixed with glycerol for $20 \mathrm{~min}$ obtaining a pulp. In the second step, starch (TPS/MMT) or mixtures of starch and xanthan (TPSX/MMT) were added (according to each specific formulation) and manually mixed to the formed pulp in the sealed plastic bags for 30 min and the final mixtures were stored in the sealed plastic bags for $24 \mathrm{~h}$ before extrusion. Each 
mixture was manually fed into the extruder (BGM EL-25: single screw, $25 \mathrm{~mm}$ diamenter, $700 \mathrm{~mm}$ lenght) for the first time to obtain the pellets of gelatinized material. These pellets were reextruded for better homogenization. The second batch of pellets obtained was fed again to the extruder, this time for the film manufacturing by blowing (50 $\mathrm{mm}$ diameter blowing matrix). Extrusion temperatures were - from feed zone to the die $-120 / 130 / 120 / 120^{\circ} \mathrm{C}$ for the pelletization steps, and $120 / 130 / 120 / 130^{\circ} \mathrm{C}$ for the blowing step. Screw rotation was kept at $35 \mathrm{rpm}$. Film sheets were cut and stored at ambient temperature and humidity until conditioning and utilization.

Table 1- Formulations employed to produce the biodegradable films.

\begin{tabular}{ccccc}
\hline Code & Starch $(\mathbf{g})$ & $\begin{array}{c}\text { Xanthan } \\
(\mathbf{g} / \mathbf{1 0 0} \mathbf{g} \text { starch })\end{array}$ & $\begin{array}{c}\text { Glycerol } \\
(\mathbf{g} / \mathbf{1 0 0} \text { starch })\end{array}$ & $\begin{array}{c}\text { Nanoclay } \\
(\mathbf{g} / \mathbf{1 0 0} \mathbf{g} \text { starch })\end{array}$ \\
\hline TPS & 100 & - & 20 & - \\
TPSX1 & 100 & 2 & 20 & - \\
TPSX2 & 100 & 4 & 20 & 2.5 \\
TPS/MMT1 & 100 & - & 20 & 5.0 \\
TPS/MMT2 & 100 & - & 20 & 2.5 \\
TPSX1/MMT1 & 100 & 2 & 20 & 5.0 \\
TPSX1/MMT2 & 100 & 2 & 20 & 2.5 \\
TPSX2/MMT1 & 100 & 4 & 20 & 5.0 \\
TPSX2/MMT2 & 100 & 4 & 20 & \\
\hline
\end{tabular}

\section{Films characterization}

\section{Thickness measurement}

The thickness was determined using a manual micrometer with $\pm 0.1 \mu \mathrm{m}$ accuracy (Mitutoyo, Brazil), and calculated as the average of 10 measurements taken at random positions on the film.

\section{Opacity}

Samples $(40 \times 40 \mathrm{~mm})$ were preconditioned at $65 \% \mathrm{RH}, 25^{\circ} \mathrm{C}$ for five days and analyzed for opacity, using a BYK Gardner colorimeter according to Sobral (2000). The equipment compared the opacity of the sample to a white $\left(\mathrm{Y}_{\mathrm{w}}\right)$ and a black $\left(\mathrm{Y}_{\mathrm{b}}\right)$ standard, according to equation: $\mathrm{Y}=\left(\mathrm{Y}_{\mathrm{b}} \cdot / \mathrm{Y}_{\mathrm{W}}\right) .100$. Results were given in percentage of opacity. All the tests were conducted in triplicate.

\section{Sorption isotherms}

Film samples were pre-dried for seven days over phosphorous pentoxide $\left(\mathrm{P}_{2} \mathrm{O}_{7}\right)$ and then were placed at $25 \pm 2{ }^{\circ} \mathrm{C}$ over saturated salt solutions in separated desiccators having desired water activities $(0.33,0.43, \quad 0.58, \quad 0.75$ and 0.90$)$ conditions (Rockland, 1960). Each film specimen was weighed at regular intervals (minimum $1 \mathrm{~h}$ and maximum $6 \mathrm{~h}$ ), and when two consecutive weighings were equal, it was assumed that an equilibrium condition was reached. Under the above conditions, an equilibrium period of three days was sufficient to establish the moisture equilibrium. Equilibrium moisture content was calculated from the increase in the mass of the dried sample after equilibration at a given water activity.

GAB (Guggenheim - Anderson - de Boer) model was used to fit the films sorption isotherm data, and monolayer values were calculated from the equations (Bizot, 1984). GAB isotherm model can be expressed as follows: $\mathrm{M}=\mathrm{m}_{0} \mathrm{CKa}_{\mathrm{w}} /\left(1-\mathrm{Ka}_{\mathrm{w}}\right)$ (1- $\mathrm{Ka}_{\mathrm{w}}+\mathrm{CKa}_{\mathrm{w}}$ ), where $\mathrm{M}$ is the equilibrium moisture content at a water activity $\left(\mathrm{a}_{\mathrm{w}}\right), \mathrm{m}_{0}$ is the monolayer value ( $\mathrm{g}$ water/ $\mathrm{g}$ solids) and $\mathrm{C}$ and $\mathrm{K}$ are the GAB constants.

\section{Scanning Electron Microscopy (SEM)}

Surface and fracture images were obtained using a FEI QUANTA 200 electron microscope (Oregon USA). Samples were previously dried in hot air circulation oven $\left(70^{\circ} \mathrm{C}\right)$ for $3 \mathrm{~h}$, fractured with liquid nitrogen for cross section images, and then kept in a closed desiccator containing calcium chloride for one week. Samples were coated with gold by low vacuum sputter coating. Images were taken at 15 and $20 \mathrm{kv}$.

\section{Fourier-Transform Infrared Spectroscopy (FT- IR)}

Samples were dried at $70^{\circ} \mathrm{C}$ for $3 \mathrm{~h}$ in hot air circulation oven, pulverized with mortar and pestle, and stored in the desiccator with calcium chloride for one week. The pulverized and dried 
samples were then mixed with potassium bromide and compressed to tablets. FTIR analysis was carried out using Shimadzu FT-IR - 8300 (Japan), with a resolution of $4 \mathrm{~cm}^{-1}$, in the range of $4000-$ $400 \mathrm{~cm}^{-1}$.

\section{Water vapor permeability (WVP)}

WVP was conducted in accordance with the modified ASTM E96-00 method (ASTM, 2000). Film samples were sealed over a $60 \mathrm{~mm}$ circular opening of a permeation cell containing calcium chloride ( $0 \%$ RH inside the cell). The set was then placed inside a desiccator containing the saturated sodium chloride solution $(75 \% \mathrm{RH}$ outside the cell), to create a 75\% RH gradient across the film. Weight gain was recorded and plotted as a function of time. The slope of each line was calculated by linear regression $\left(r^{2}>0.99\right)$ and WVTR (water vapor transmission rate) was calculated from the slope of the straight line $(\mathrm{g} / \mathrm{s})$ divided by the transfer area $\left(\mathrm{m}^{2}\right)$. WVP $\left(\mathrm{g} . \mathrm{Pa}^{-1} . \mathrm{s}\right.$ $\left.{ }^{1} \cdot \mathrm{m}^{-1}\right)$ was calculated as WVP $=\left[\mathrm{WVTR} / \mathrm{S}\left(\mathrm{R}_{1}-\right.\right.$ $R_{2}$ ).D]; where $S$ is the saturation vapor pressure off water $(\mathrm{Pa})$ at the temperature $\left(25^{\circ} \mathrm{C}\right), \mathrm{R}_{1}$ is the $\mathrm{RH}$ inside the desiccator, $\mathrm{R}_{2}$ is the $\mathrm{RH}$ inside the permeation cell, and $\mathrm{D}$ is the thickness of the film (m). All tests were conducted in triplicate.

\section{Mechanical properties}

The tensile properties were determined using TA.TX2i Stable Micro Systems texture analyzer (Surrey - England) in accordance with ASTM D882-91 method (1996). Sample strips (25.4 x $100.0 \mathrm{~mm}$ ) of each formulation were conditioned at $25^{\circ} \mathrm{C}$ over saturated salt solutions in separated desiccators to a desired relative humidity $(32,65$, and $98 \% \mathrm{RH}$ ) (Rockland, 1960) for $72 \mathrm{~h}$. To conduct the test, the strips were clamped between pneumatic grips $(50 \mathrm{~mm}$ initial distance between the grips) and distended at $50 \mathrm{~mm} . \mathrm{min}^{-1}$. Force (N) and deformation $(\mathrm{mm})$ where recorded, in order to determine the stress at break (MPa) and strain at break $(\%)$.

\section{Statistical analysis}

ANOVA variance analysis $(\mathrm{p} \leq 0.05)$ was conducted using STATISTICA 7.0 (Statsoft, Oklahoma).

\section{RESULTS AND DISCUSSION}

\section{Opacity and visual aspect}

The formulations were blown without any problems and none of the films presented stick surface during or right after the extrusion. Films containing xanthan gum (TPX1 and TPX2) were characterized by a rough surface, and this characteristic was more evident with the increase of xanthan gum concentration. Films produced with the nanoclays and xanthan gum presented more homogeneous surface. All the formulations gave films with good resistance to handling, folding and crushing. None of the samples showed resistance to shredding.

Only nanoclays addition affected significantly the opacity of the produced films (Table 2), which were not totally transparent.

Nanoclays addition decreased the opacity of the TPS, TPSX1 and TPSX2 films (Table 2). This could indicate that xanthan dispersed more homogeneously in the starch matrix with nanoclays addition, forming more translucent films. According to Chen et al. (2008) the transparency provides information about the compatibility of films components; therefore, nanometer size particles could interact well and improve the transparency of starch films.

Table 2 - Opacity and water vapor permeability (WVP) of biodegradable films.

\begin{tabular}{|c|c|c|c|c|}
\hline Code & $\begin{array}{c}\text { Xanthan }(\mathrm{g} / 100 \mathrm{~g} \\
\text { starch })\end{array}$ & $\begin{array}{c}\text { Nanoclay }(g / 100 \mathrm{~g} \\
\text { starch) }\end{array}$ & $\begin{array}{c}\text { Opacity } \\
(\%)\end{array}$ & $\begin{array}{c}\text { WVP } \\
\left(\mathrm{gm}^{-1} \mathrm{~s}^{-1} \mathrm{~Pa}^{-1}\right) \times 10^{10}\end{array}$ \\
\hline TPS & - & - & $51.02 \pm 1.21 \mathrm{a}$ & $1.40 \pm 0.21 \mathrm{a}$ \\
\hline TPSX1 & 2.0 & - & $49.94 \pm 1.77 \mathrm{a}$ & $1.58 \pm 0.11 \mathrm{a}$ \\
\hline TPSX2 & 4.0 & - & $55.59 \pm 5.02 \mathrm{a}$ & $1.57 \pm 0.10 \mathrm{a}$ \\
\hline TPS/MMT1 & - & 2.5 & $44.19 \pm 1.21 \mathrm{c}$ & $1.08 \pm 0.11 \mathrm{~b}$ \\
\hline TPS/MMT2 & - & 5.0 & $43.59 \pm 1.50 c$ & $0.99 \pm 0.13 b$ \\
\hline TPSX1/MMT1 & 2.0 & 2.5 & $45.97 \pm 0.32 b$ & $1.12 \pm 0.09 \mathrm{~b}$ \\
\hline TPSX1/MMT2 & 2.0 & 5.0 & $46.12 \pm 0.38 b$ & $0.90 \pm 0.08 b$ \\
\hline TPSX2/MMT1 & 4.0 & 2.5 & $50.84 \pm 0.13 \mathrm{a}$ & $1.07 \pm 0.01 \mathrm{~b}$ \\
\hline TPSX2/MMT2 & 4.0 & 5.0 & $48.37 \pm 1.14 \mathrm{a}, \mathrm{b}$ & $1.06 \pm 0.20 \mathrm{~b}$ \\
\hline
\end{tabular}

Means at same column with different letters are significantly different $(\mathrm{p} \leq 0.05)$. 


\section{Scanning electron microscopy (SEM)}

Films containing only starch and glycerol (TPS films) presented homogeneous and smooth surface (Fig. 1a). Starch/xanthan films (TPSX1 and TPSX2) showed increasingly rougher surface with the increase of xanthan gum addition (Fig. $1 \mathrm{~b}$ and 1c). Sereno et al. (2007) observed that xanthan original helical structure was lost inside the extruder and on cooling, a continuous network was formed, which consisted in a mixture of nonhelical amorphous matrix maintained by the helical junction regions involving the segments of the molecule of different lengths. The images of starch-xanthan films (Fig. 1b and 1c) obtained in this work seemed to agree with the mentioned observations, considering that the rough appearance of the surfaces resembled the structures described by the ahead mentioned author. Furthermore, cross-section images (Fig. 2) suggested that, during the extrusion, xanthan gum mixed matrix was concentrated on both the surfaces of the films (in each film's micrograph only one surface could be observed, but the both surfaces showed the same aspect), while an amorphous material in a more compact form, probably gelatinized starch, seemed to be more concentrated between both surfaces.

Starch-nanoclay films (TPS/MMT1 and TPS/MMT2) showed continuous matrices (Fig. 1d and $1 \mathrm{e}$ ), but their surfaces were less smoother than the TPS films. The images were similar to those obtained by others authors (Zhang et al., 2007).

Starch-xanthan-nanoclay films (TPSX/MMT) presented more homogeneous surfaces than the starch-xanthan films, especially for the films formulated with $2.0 \mathrm{~g}$ xanthan $/ 100 \mathrm{~g}$ starch (Fig. If and $1 \mathrm{~g}$ ). These images suggested that the introduction of nanoclays in the starch-xanthan films improved their properties by promoting a better biopolymeric interaction. According to Benchabane and Bekkour (2006), xanthan gum being anionic polymer could not penetrate nanoclay's interlayer space, but it could act on the external surface of the clay particles by coating them.

\section{Sorption isotherms}

The moisture sorption isotherms of the starch films are displayed in Figure 3 and the monolayer value calculated from the GAB model are shown in Table 3. Films without nanoclays presented the highest monolayer values, while the incorporation of nanoclays decreased this response (Table 3). Xanthan addition slightly increased the monolayer values of the films and this could occur because the gum was a hydrophilic material (Table 3). The monolayer value indicated the maximum amount of water that could be adsorbed in a single layer per gram of dry film; i.e, it represented a measure of the number of sorbing sites (Levine and Slade, 1991).

Probably, the interactions between the polymeric matrix and the nanoclay, as observed by FT-IR (discussed below), originated a decrease in the sorption capacity of manufactured films. According to Huang et al. (2004), starch hydroxyl groups could interact directly either with the sodium ion of the clay (like the water molecules do), or with its edge hydroxyl groups, making a very compatible system. Tunc et al. (2007) reported that the reduction in the water sensitivity in the hydrophilic films occurs because a different surface is formed in the presence of MMT, due to the establishment of specific interactions between the MMT, glycerol and the polymer. Tang et al. (2008) reported that the nanostructure of the polymer/clay hybrids depended on the compatibility and interactions between the base polymer, plasticizers and silicate layers. Strong polar-polar interactions between the starch, glycerol, water and clay surface, established a competition mechanism that could explain the decrease in the water sorption capacity of the films produced with the nanoclays. 

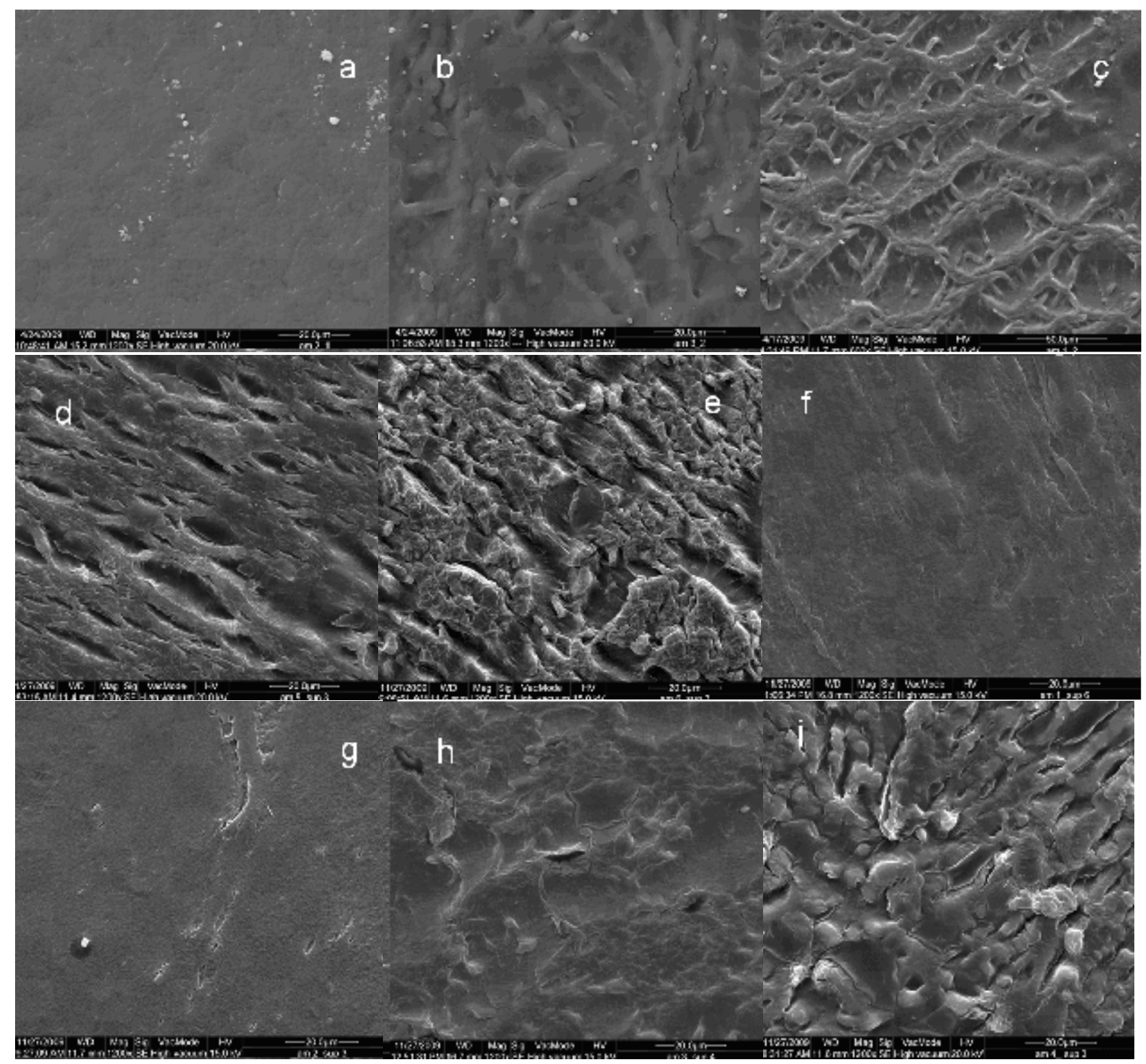

Figure 1 - SEM micrographs of surfaces of biodegradable starch films: (a) TPS; (b) TPSX1; (c)TPSX1; (d) TPS/MMT1; (e)TPS/MMT1; (f) TPSX1/MMT1; (g)TPSX1/MMT2; (h)TPSX2/MMT1; (i)TPSX2/MMT1.

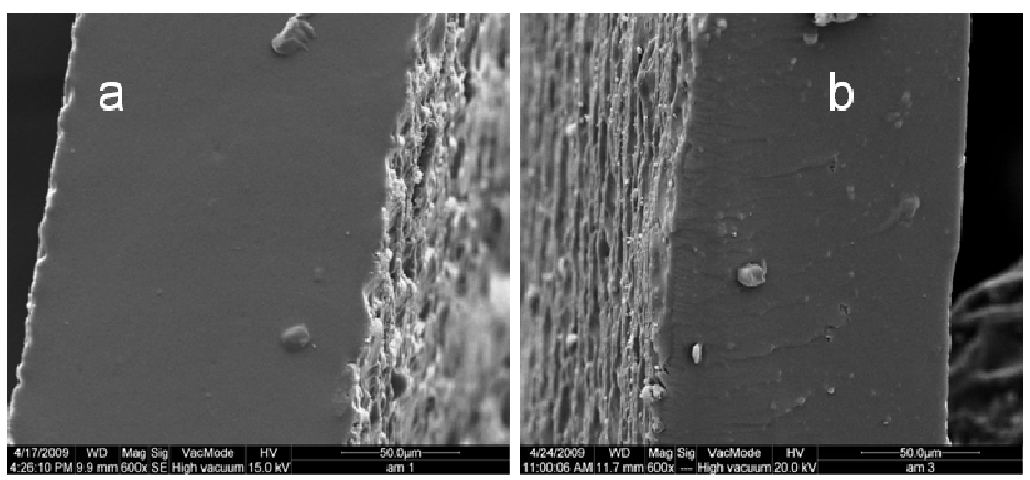

Figure 2 - SEM micrographs of cross-sections of biodegradable starch films: (a) TPSX1 and (b) TPSX2. 


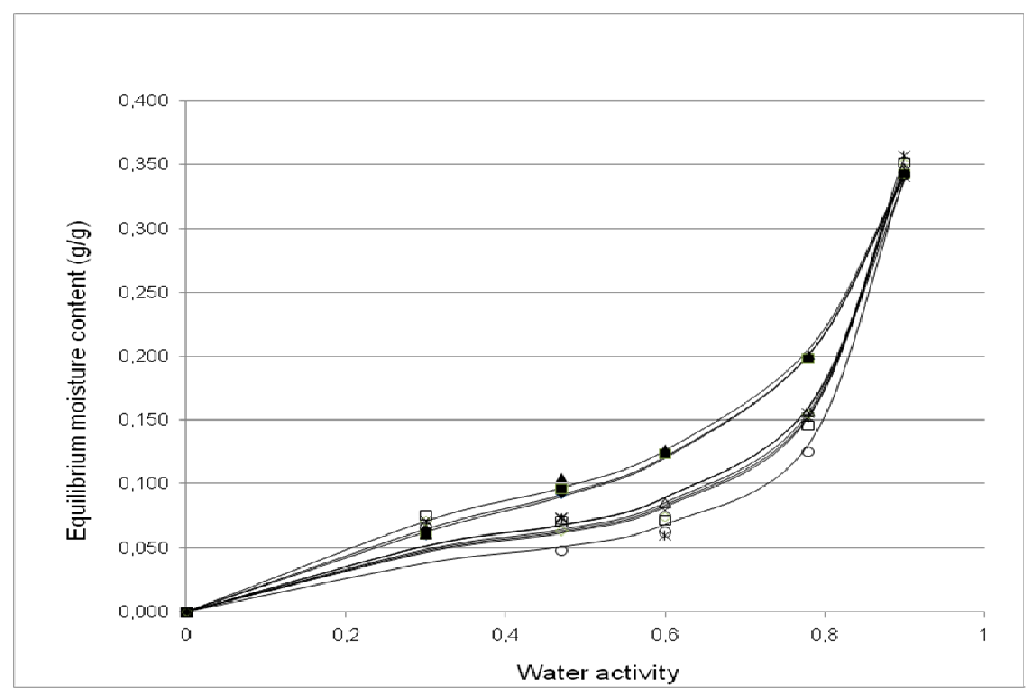

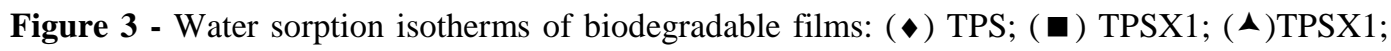
$(*) \quad$ TPS/MMT1; $\quad(\diamond)$ TPS/MMT1; $\quad(\mathrm{x}) \quad$ TPSX1/MMT1; $\quad(\Delta)$ TPSX1/MMT2;

(O)TPSX2/MMT1; ( )TPSX2/MMT1. The lines are derived from GAB model.

Table 3 - Monolayer value of biodegradable films calculated from GAB model.

\begin{tabular}{ccccc}
\hline Code & Xanthan $\mathbf{( g / 1 0 0 ~ g ~ s t a r c h ) ~}$ & Nanoclay $\mathbf{( g / 1 0 0 ~ g ~ s t a r c h ) ~}$ & $\mathbf{~ m}_{\mathbf{0}}$ (g water/g solids) & $\mathbf{R}^{\mathbf{2}}$ \\
\hline TPS & - & - & 0.067 & 0.99 \\
TPSX1 & 2.0 & - & 0.075 & 0.99 \\
TPSX2 & 4.0 & - & 0.074 & 0.99 \\
TPS/MMT1 & - & 2.5 & 0.035 & 0.98 \\
TPS/MMT2 & - & 5.0 & 0.037 & 0.99 \\
TPSX1/MMT1 & 2.0 & 2.5 & 0.038 & 0.99 \\
TPSX1/MMT2 & 2.0 & 5.0 & 0.039 & 0.99 \\
TPSX2/MMT1 & 4.0 & 2.5 & 0.029 & 0.99 \\
TPSX2/MMT2 & 4.0 & 5.0 & 0.036 & 0.99 \\
\hline
\end{tabular}

$\mathrm{M}=\mathrm{m}_{0} \mathrm{CKaw} /\left(1-\mathrm{Ka}_{\mathrm{w}}\right)\left(1-\mathrm{Ka}_{\mathrm{w}}+\mathrm{CKa}_{\mathrm{w}}\right)$, where $\mathrm{M}$ is the equilibrium moisture content at a water activity $\left(\mathrm{a}_{\mathrm{w}}\right), \mathrm{m}_{0}$ is the monolayer value (g water/g solids), and $\mathrm{C}$ and $\mathrm{K}$ are the constants.

\section{FT-IR}

FT-IR analysis of the films were performed to identify the potential interactions between the starch, xanthan, nanoclays and glycerol. Infrared spectra of the film samples are shown in Figure 4. All the spectra showed a wide absorption band corresponding to $\mathrm{O}-\mathrm{H}$ stretching, around 3446$3420 \mathrm{~cm}^{-1}$, which indicated the occurrence of intense $\mathrm{H}$-bonding interaction between the components of the films during the manufacturing process. According to Pavia et al. (2001), a peak at $3600 \mathrm{~cm}^{-1}$ indicated unbound $\mathrm{O}-\mathrm{H}$ stretching, however, the presence of hydrogen interactions shifted the band to a lower frequency, as observed in this work.

Figure 4 shows also - for all formulations - the presence of peaks around $1656-1640 \mathrm{~cm}^{-1}$ associated with angular $\mathrm{O}-\mathrm{H}$ bending of water molecules (Mano and Mendes, 1999; Dragunski and Pawlika, 2001), suggesting that the intermolecular hydrogen interactions might be also due to starch, xanthan gum, nanoclays and glycerol interaction with the water. According to Dean et al. (2007), the key interaction between the unmodified layered silicates and water was the ion-dipole interaction between the sodium ion (located in the intergallery space of the clay) and the dipole of the water molecule. Starch hydroxyl groups could also interact directly with the sodium ion of the clay (as the water molecules did) or with its edge hydroxyl groups, making a very compatible system (Huang et al., 2004).

Peaks occurring at $2900 \mathrm{~cm}^{-1}$ corresponded to $-\mathrm{C}$ $\mathrm{H}$ stretching; $\mathrm{H}-\mathrm{C}-\mathrm{H}$ and $-\mathrm{C}-\mathrm{O}-\mathrm{H}$ conjugated bending vibrations appeared as weak and broad peaks at $1440-1220 \mathrm{~cm}^{-1}$. In films manufactured 
by the extrusion, these peaks appeared in the regions of lower frequencies, probably due to the presence of hydrogen interaction, either between the polymer molecules or between the polymers and water.

All the films showed strong peaks at $1200-900$ $\mathrm{cm}^{-1}$, corresponding to $-\mathrm{C}-\mathrm{O}$ bond stretching of starch and xanthan (Fang et al., 2002). The characteristic peak near $1150 \mathrm{~cm}^{-1}$ was ascribed to $\mathrm{C}-\mathrm{O}$ bond stretching of the $\mathrm{C}-\mathrm{O}-\mathrm{H}$ group in the starch and xanthan, while the peak at 1080 was attributed to C-O-C group in the anydroglucose ring. In all the films, the peaks were at $860-747$ $\mathrm{cm}^{-1}$, which were related to alkenes $\mathrm{C}-\mathrm{H}$ stretching, present both in the starch and xanthan gum (Mano and Mendes, 1999).

In general, it was worth noting that the shape and location of the main peaks in the films containing starch, xanthan, glycerol and nanoclays were very close to those in the pure starch. This suggested that the interactions of starch-starch molecules dominated and were stronger than those of starchxanthan or starch-nanoclays molecules in the blending system.

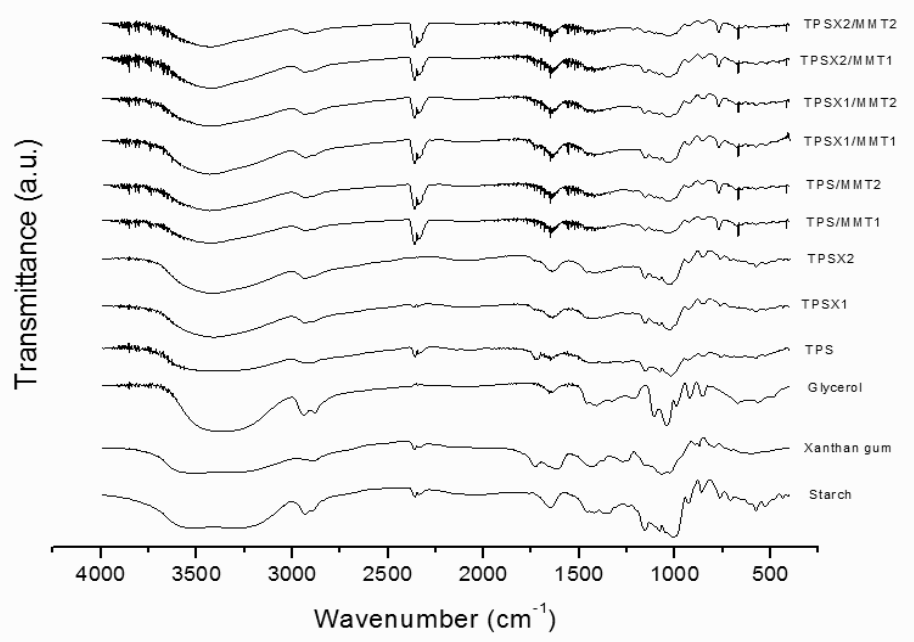

Figure 4 - FT-IR spectra of starch, xanthan gum, glycerol and biodegradable starch films.

\section{Water vapor permeability (WVP)}

Since the films manufactured in this work were intended to be used in the packaging materials, WVP should be as low as possible. For all the samples, WVP values ranged from 0.90 to $1.58 \mathrm{x}$ $10^{-10} \mathrm{gm}^{-1} \mathrm{~s}^{-1} \mathrm{~Pa}^{-1}$ (Table 2). Although xanthan addition did not have significant effect on the permeability, all the samples containing the nanoclays showed the lowest WVP values (Table 2). When $2.5 \%$ MMT was incorporated into starch-nanoclay composites, WVP decreased in comparison with the TPS samples. Adding more nanoclay, however, did not result in further improvements. These results agreed with data reported by other authors (Park et al., 2002; Chiou et al., 2007). The presence of MMT in the films matrices increased the tortuosity of the diffusive path, making more difficult the penetration of molecules like water, what resulted in the materials with excellent barrier properties. Moreover, the exposed hydroxyl groups of starch shielded by highly dispersive MMT layers also decreased the water sensitive of TPS (Wang et al., 2009; Azeredo, 2009).

When compared to the synthetic polymers, the films obtained in this work had slightly higher WVP values than the cellophane $\left(0.84 \times 10^{-10} \mathrm{gm}^{-}\right.$ $\left.{ }^{1} \mathrm{~S}^{-1} \mathrm{~Pa}^{-1}\right)$ and higher than low density polyethylene (LPDE) $\left(0.0036 \times 10^{-10} \mathrm{gm}^{-1} \mathrm{~s}^{-1} \mathrm{~Pa}^{-1}\right)$ (Shelhammer and Krochta, 1997). However, xanthan-starchnanoclay films had lower WVP values than other nanoclay films like corn starch plasticized with glycerol and citric acid $\left(2.0 \times 10^{-10} \mathrm{gm}^{-1} \mathrm{~s}^{-1} \mathrm{~Pa}^{-1}\right)$ (Wang et al., 2009) and pea starch/ZnO carboxymethylcellulose plasticized with glycerol $\left(1.5-4.5 \times 10^{-10} \mathrm{gm}^{-1} \mathrm{~s}^{-1} \mathrm{~Pa}^{-1}\right.$ ) (Yu et a., 2009). 


\section{Mechanical properties}

As noted at Figure 5, xanthan gum decreased the stress at break of the samples when employed at low level (TPSX1) and probably in this case, a weaker matrix was formed during the film production, and when the gum was employed at $4.0 \mathrm{~g} / 100 \mathrm{~g}$ starch (TPSX2) the stress at break increased. Nanoclays addition improved this mechanical property in all the formulations, which could be attributed both to the fact that the nanoclays could function as rigid fillers incorporated to starch matrix and also to the interactions between the polymeric matrix and layered silicates via formation of hydrogen bonds (Tunc et al., 2007).

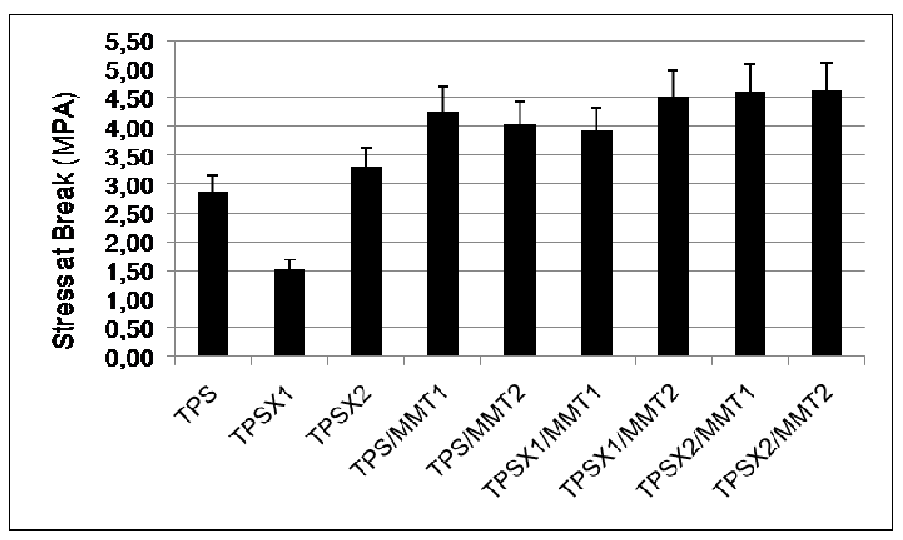

Figure 5 - Stress at break of biodegradable starch films.

Strain at break (Fig. 6) increased with the addition of xanthan gum to the TPS starch (TPSX1 and TPSX2), and the TPSX1 formulation showed the higher elongation. Xanthan gum's ability to form stable tridimensional networks in the water, as well as its helical structure, suggested that its addition to the system would lead to increasing of strain at break. When compared to the TPS films, films produced with the nanoclays showed higher values for the strain at break when prepared with $2.0 \mathrm{~g}$ xanthan $/ 100 \mathrm{~g}$ starch.
Films produced with xanthan gum and nanoclays (Fig.5 and 6) presented a good combination of mechanical properties, specially the films produced with $2.0 \mathrm{~g}$ xanthan gum/100 g starch (TPSX1/MMT1 and TPSX1/MMT2), which showed high stress and strain at break values and this could be related to the good interaction between the employed polymers as observed by SEM, these films showed homogeneous surfaces when compared to the others (Fig.1f and 1g).

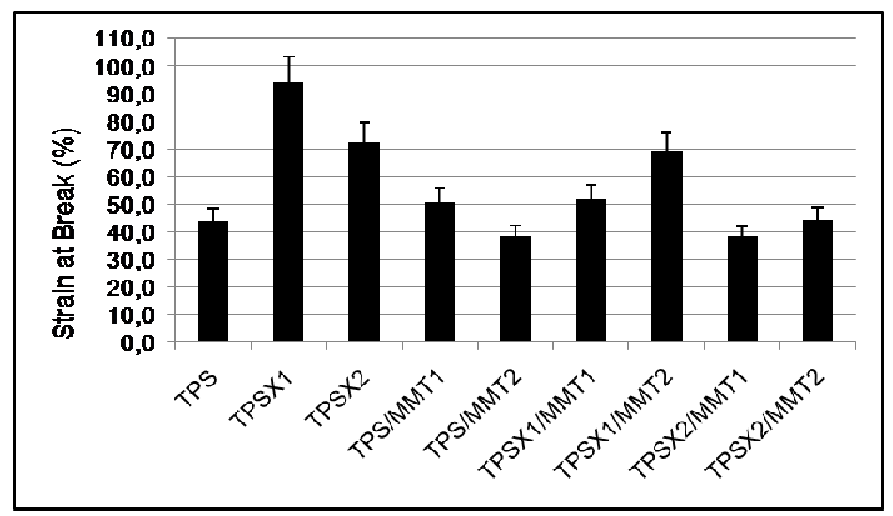

Figure 6 - Strain at break of biodegradable starch films. 


\section{CONCLUSIONS}

Xanthan gum addition affected mechanical properties of starch films, improving their elongation. Films produced with xanthan (2.0 $\mathrm{g} / 100 \mathrm{~g}$ starch) and nanoclays ( 2.5 or $5.0 \mathrm{~g} / 100 \mathrm{~g}$ starch) presented the better combination of mechanical properties, with high stress and strain at break values. Nanoclays addition at $2.5 \mathrm{w} \%$ was sufficient to decrease water vapor permeability and water sorption capacity and to increase the stress at break of produced films. These materials are a valid answer to produce low cost, highly competitive and pioneering environmentally friendly materials. Moreover, because of the increasing concerns about the sustainable development, as well as the escalating prices and global demand and for saving the fossil resources, agro-based materials now represent an interesting option to replace the conventional plastics.

\section{ACKNOWLEDGEMENTS}

The authors wish to thank the Conselho Nacional de Desenvolvimento Cientifico e Tecnológico (CNPq-No. 577146/2008-4) of Brazil for the financial support.

\section{REFERENCES}

Achayuthakan, P.; Suphantharika, M. (2008), Pasting and rheological properties of waxy corn starch as affected by guar gum and xanthan gum. Carbohyd. Polym., 71, 9-17.

ASTM, 1996. Standard test methods for tensile properties of thin plastic sheeting - D882-91. In: Annual Book of ASTM Standards. Philadelphia.

ASTM, 2000. Standard test methods for water vapor transmission of material - E-96-00. In: Annual Book of ASTM Standards. Philadelphia.

Azeredo, H.M.C. (2009), Nanocomposites for food packaging applications. Food Res. Int., 42, 12401253.

Benchabane A., Bekkour, K. (2006), Effects of anionic additives on the rheological behavior of aqueous calcium montmorillonite suspensions, Rheol. Acta, 45, 425-434.

Bizot, H. (1984), Using the GAB model to construct sorption isotherms. In Physical properties of foods, Ed R. Jowitt, F. Escher, B. Hallistrom, H. F. T. Meffert, W. E. L. Spiess, and G. Vos. Applied Science Publishers, London. pp. 27-41.
Chen, Y.; Cao, X.; Chang, P.R.; Huneault, M.A. (2008), Comparative study on the films of poly (vinyl alcohol)/pea starch nanocrystals and poly(vinyl alcohol)/native pea starch. Carbohyd. Polym., 73, 817.

Chiou, B.S., Wood, D.; Yee, E.; Imam, S.H.; Glenn, G.M.; Orts, W.J. (2007), Extruded starch-nanoclay nanocomposites: effects of glycerol and nanoclay concentration. Polym. Eng. Sci., 1898-1904.

Chivrac, F.; Kadlecova, Z.; Pollet, E.; Averous, L. (2006), Aromatic Copolyester-Based NanoBiocomposites: Elaboration, Structural Characterization and Properties. J Polym. Environm., 14, 393- 401 .

Chivrac, F.; Pollet, E.; Avérous, L. (2009), Progress in nao-biocomposites based on polyssacharides and nanoclays. Mater. Sci. Eng. R, 67, 1-17.

Dean, K.; Yu, L.; Wu, D.Y. (2007), Preparation and characterization of meltextruded thermoplastic starch/clay nanocomposites. Compos. Sci. Technol., 67, 413-421.

Dragunski, D.C.; Pawlika, A. (2001), Preparation and characterization of starch grafted with toluene poly (propylene oxide) diisocyanate. Mater. Res., 4, 77 81.

Fang, J.M.; Fowler, P.A.; Tomkinson, J. (2002), The preparation and characterization of a series of chemically modified potato starches. Carbohyd. Polym., 47, 245-252.

Garcia-Ochoa, F.; Santos, V.; Casas, J.; Gomez, E. (2000), Xanthan gum: production, recovery, and properties. Biotech. Adv., 18, $549-579$.

Huang, M.F.; Yu, J.G; Ma, X.F. (2004), Studies on the properties of Montmorillonite-reinforced thermoplastic starch composites. Polymer, 45, 70177023.

Lepoittevin, B.; Pantoustier, N.; Devalckenaere, M.; Alexandre, M.; Kubies, D.; Calberg, C.; Jerome, R.; Dubois, P. (2002), Poly (caprolactone)/clay nanocomposites by in-situ intercalative polymerization catalyzed by dibutyltin dimethoxide. Macromolecules, 35, 8385-8390.

Levine, H.; Slade, L. (1991),Water relationships in foods. 1nd. Plenum Press.

Mali, S.; Sakanaka, L.S.; Yamashita, F.; Grossman, M.V.E. (2005), Water sorption and mechanical properties of cassava starch films and their relation to plasticizing effect. Carbohyd. Polym., 60, 283 - 289.

Mali, S.; Grossmann, M.V.E.; Garcia, M.A.; Martino, M.N.; Zaritzky, N.E. (2006), Effects of controlled storage on thermal, mechanical and barrier properties of plasticized films from different starch sources. $J$. Food Eng., 75, 453 - 460.

Mano, E.B.; Mendes, L.C. (1999), Introdução a Polímeros, 2nd ed. Edgard Blucher Ltda, São Paulo.

Miladinov, V.D.; Hanna, M.A. (1996), Apparent viscosity of co-extruded starch and xanthan gum. Ind. Crops Prod., 5, 183 - 188. 
Miladinov, V.D.; Hanna, M.A. (1995), Apparent viscosity of starch and xanthan gum extruded with cross-linking agent. Ind. Crops Prod., 4, 261 - 271.

Navarro, A.S.; Martino, M.N.; Zaritzky, N.E. (1995), Effects of freezing rate on rheological behavior of systems based on starch and lipid phase. J. Food Eng., 26, 481 - 495.

Paul M.A.; Alexandre, M.; Dege'e, P.; Henrist, C.; Rulmont, A.; Dubois, P. (2003), New nanocomposite materials based on plasticized poly (L-lactide) and organo-modified montmorillonites: thermal and morphological study. Polymer, 44, 443-50.

Park, H.M.; Li , X.; Jin, C. Z.; Park, C. Y.; Cho, W. J.; Ha. C. S. (2002), Preparation and properties of biodegradable thermoplastic starch/clay hybrids. Macromol. Mater. Eng., 287, 553-558.

Park, H.M.; Lee, W.K.; Park, Y.; Cho, W.J.; Ha, C.S. (2003), Environmentally friendly polymer hybrids Part I Mechanical, thermal, and barrier properties of thermoplastic starch/clay nanocomposites. J Material Sci., 38, $909-915$.

Pavia, D.L.; Lampman, G.M.; Kriz, G.S. (2001), Introduction to Spectroscopy: a guide for students of organic chemistry, $3^{\text {rd }}$ ed. Thomson Learning Inc., Bellingham (USA).

Rockland, L.B. (1960), Saturated salt solutions for static control of relative humidity. Anal. Chem., 32, 1375 - 1376.

Sanchez-Garcia, M.D.; Gimenez, E.; Lagaron, J.M. (2008), Morphology and barrier properties of nanobiocomposites of poly (3-hydroxybutyrate) and layered silicates. J. Appl. Polym. Sci., 108, 27872801.

Sereno, N; Hill, S.; Mitchell, J. (2007), Impact of extrusion process on xanthan gum behavior. Carbohydrate Research, 342, 1333 - 1342.

Shellhammer, T. H.; Krochta J. M. (1997), Whey protein emulsion film performance as affected by lipid type amount. J Food Sci., 62, 390-394.

Soares, R.; Lima, R.; Oliveira, R.; Pires, A.; Soldi, V. (2005), Thermal degradation of biodegradable edible films based on xanthan and starches from different sources. Polym. Degrad. Stabil., 90, 449 - 454.

Sobral, P.J.A. (2000), Influência da espessura de biofilmes feitos à base de proteínas miofibrilares sobre suas propriedades funcionais. Pesqui. Agropecu. Bras., 35, 1 - 14.
Su, L., Ji, W.K., Lan, W.Z., Dong, X.Q. (2003), Chemical modifications of xanthan gum to increase dissolution rate. Carbohyd. Polym., 53, 497 - 499.

Tang,X.; Alavi, S.; Herald, T.J. (2008), Effects of plasticizers on the structure and properties of starchclay nanocomposite films. Carbohyd. Polym., 74, 552-558.

Thunwall M.; Kuthanova V., Boldizar A.; Rigdahl M. (2008), Film blowing of thermoplastic starch. Carbohyd. Polym., 71, 591-597.

Tunc, S.; Angellier, H.; Cahyana, Y.; Chalier, P.; Gontard N.; Gastaldi, E. (2007), Functional properties of whea gluten/montmorillonite nanocomposite fims processed by casting. $J$. Membrane Sci, 289, 159-168.

Veiga-Santos, P.; Oliveira, L.; Cereda, M.; Alves, A.; Scamparini, A. (2005a), Mechanical properties, hydrophilicity and water activity of starch-gum films: effect of additives and deacetylated xanthan gum. Food Hydrocolloid., 19, 341 - 349.

Wang, F.; Sun, Z.; Wang, Y.J. (2001), Study of xanthan gum/waxy cornstarch interaction by viscometry. Food Hydrocolloid, 15, 575 - 581.

Yoshimura, M.; Takaya, T.; Nishinari, K. (1999), Effects of xyloglucan on the gelatinization and retrogradation of cornstarch studied by rheology and differential scanning calorimetry. Food Hydrocolloid, 13, $101-111$.

Wang, N.; Xingxiang, Z.; Han, N.; S. Bai (2009), Effect of citric acid and processing on the performance of thermoplastic starch/ montmorillonite composites. Carbohyd. Polym., 76, 68.

Weiss, J.; Takhistov, P.; McClements, D.J. (2006), Functional materials in food nanotechnology. J. Food Sci., 71, 107-116.

Yu, J.; Yang, J.; Liu, B.; Ma X. (2009),Preparation and characterization of glycerol plasticized pea stacg/ZnO-carboxymethylcellulose sodium nanocomposites. Biores. Technol., 100, 2832-2841.

Zhang, Q.; Yu, X.; Xie, Z.Z.; Naito, X.L.; Kagawa, Y. (2007), Preparation and crystalline morphology of biodegradable starch/clay nanocomposites. Polymer, 48, 7193-7200.
Received: September 09, 2010; Revised: December 15, 2010; Accepted: September 12, 2011. 


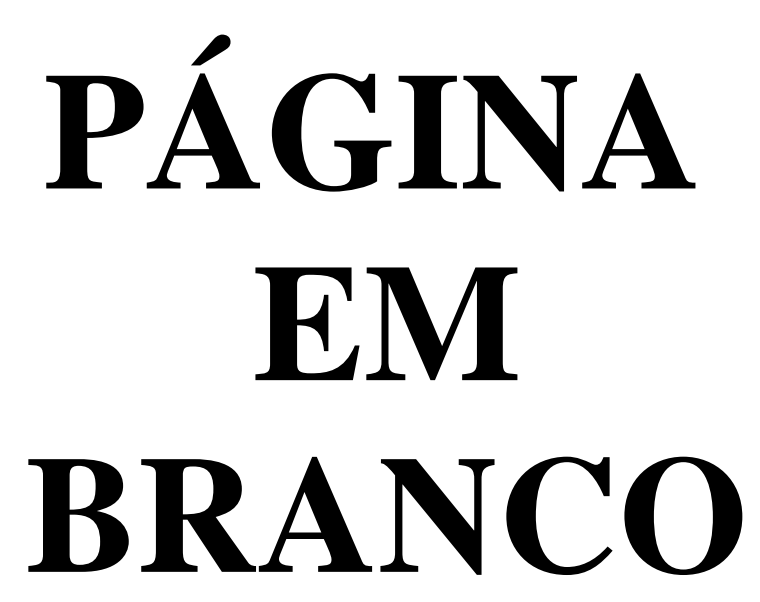

